\title{
A case report of novel mutation in PRF1 gene, which causes familial autosomal recessive hemophagocytic lymphohistiocytosis
}

Mohammad Reza Bordbar ${ }^{1}$, Farzaneh Modarresi ${ }^{2}$, Mohammad Ali Farazi Fard ${ }^{3}$, Hassan Dastsooz ${ }^{3}$, Nader Shakib Azad ${ }^{1}$ and Mohammad Ali Faghihi ${ }^{2 *}$

\begin{abstract}
Background: Hemophagocytic Lymphohistiocytosis (HLH) is a life-threatening immunodeficiency and multi-organ disease that affects people of all ages and ethnic groups. Common symptoms and signs of this disease are high fever, hepatosplenomegaly, and cytopenias. Familial form of HLH disease, which is an autosomal recessive hematological disorder is due to disease-causing mutations in several genes essential for NK and T-cell granulemediated cytotoxic function. For an effective cytotoxic response from cytotoxic T lymphocyte or NK cell encountering an infected cell or tumor cell, different processes are required, including trafficking, docking, priming, membrane fusion, and entry of cytotoxic granules into the target cell leading to apoptosis. Therefore, genes involved in these steps play important roles in the pathogenesis of HLH disease which include PRF1, UNC13D (MUNC13-4), STX11, and STXBP2 (MUNC18-2).

Case presentation: Here, we report a novel missense mutation in an 8-year-old boy suffered from hepatosplenomegaly, hepatitis, epilepsy and pancytopenia. The patient was born to a first-cousin parents with no previous documented disease in his parents. To identify mutated gene in the proband, Whole Exome Sequencing (WES) utilizing next generation sequencing was used on an Illumina HiSeq 2000 platform on DNA sample from the patient. Results showed a novel deleterious homozygous missense mutation in PRF1 gene (NM_001083116: exon3: c. 1120 T > G, p.W374G) in the patient and then using Sanger sequencing it was confirmed in the proband and his parents. Since his parents were heterozygous for the identified mutation, autosomal recessive pattern of inheritance was confirmed in the family.
\end{abstract}

Conclusions: Our study identified a rare new pathogenic missense mutation in PRF1 gene in patient with HLH disease and it is the first report of mutation in PRF1 in Iranian patients with this disease.

Keywords: Hemophagocytic Lymphohistiocytosis (HLH), PRF1, Case report, Novel mutation

\footnotetext{
*Correspondence: MFaghihi@med.miami.edu

${ }^{2}$ Center for Therapeutic Innovation, Department of Psychiatry and Behavioral

Sciences, University of Miami Miller School of Medicine, 1501 NW 10th Ave,

BRB 508, Miami, FL 33136, USA

Full list of author information is available at the end of the article
}

(c) The Author(s). 2017 Open Access This article is distributed under the terms of the Creative Commons Attribution 4.0 International License (http://creativecommons.org/licenses/by/4.0/), which permits unrestricted use, distribution, and reproduction in any medium, provided you give appropriate credit to the original author(s) and the source, provide a link to the Creative Commons license, and indicate if changes were made. The Creative Commons Public Domain Dedication waiver (http://creativecommons.org/publicdomain/zero/1.0/) applies to the data made available in this article, unless otherwise stated. 


\section{Background}

Hemophagocytic lymphohistiocytosis (HLH) is an uncommon hyper-inflammatory syndrome with high mortality associated with different conditions, including neoplastic, infectious, autoimmune, or hereditary diseases [1]. Neuropathologic findings and neurologic symptoms have been identified approximately in $75 \%$ of pediatric cases, including seizures, meningitis, encephalopathy, ataxia, hemiplegia, cranial nerve palsies, mental status changes, or simply irritability [2]. In magnetic resonance imaging (MRI) studies some brain findings may be observed, which include the increase of nodular parenchymal lesions, leptomeningeal enhancement, demyelization, and atrophy [3]. The incidence of HLH has been estimated to be 1 to 225 per 300000 live births and is reported in all ages, races and both genders $[1,2,4]$. HLH is grouped into two forms, which include familial type due to genetic mutations affecting the cytotoxic function of $\mathrm{T}$ lymphocytes and natural killer (NK) cells or acquired form presenting in different conditions such as infectious, malignant, rheumatologic, or metabolic diseases $[1,5]$. HLH is a medical emergency and must be suspected in patients affected by unexplained cytopenias and fever at any age [6]. There are no any gold standard confirmatory laboratory tests for HLH, which makes it difficult to confirm the disorder in patients. This is due to the fact that laboratory testing can show false negative results and lack specificity, or may take times to perform the tests which are not useful in a clinical emergency [7].

The diagnostic criteria for acquired HLH include fever; cytopenias affecting at least 2 of 3 lineages in the peripheral blood; splenomegaly; hyperferritinemia; hemophagocytosis in the bone marrow, spleen, or lymph nodes; hypertriglyceridemia and/or hypofibrinogenemia; low or absent NK-cell activity determined by the $51-\mathrm{Cr}$ release assay; and high levels of sCD25. Five of these eight criteria are essential for diagnosis of acquired HLH, but in familial cases with a known genetic abnormality (FHL with mutations), the diagnosis can be conducted without consideration of these five criteria [8-10]. Five different forms of FHL have been described based on defects in different genetic material and genes, including chromosome arm 9q mutations (FHL1), PRF1 (FHL2), UNC13D (MUNC13-4) (FHL3), STX11 (FHL4), and STXBP2 (MUNC18-2) (FHL5) [11-17]. To date, several mutations have been reported across exons and exon-intron boundaries of these genes. Therefore, mutation screening for HLH is complicated. However, molecular genetic approaches using next generation sequencing can be very useful in identification of familial cases suspected for HLH. Therefore, the purpose of this study was to identify disease causing mutation in a boy diagnosed with HLH.

\section{Case presentation}

An 8-year-old boy was admitted to the hematology department in Namazi Hospital (Shiraz, Iran) due to clinical findings such as fever, jaundice, hepatosplenomegaly, and pancytopenia. Laboratory studies showed notable abnormal findings related to liver function tests and coagulation profile. He had an increased level of AST, ALT, $\mathrm{LDH}$, total and direct bilirubin, prolonged prothrombin time (PT), and activated partial thromboplastin time (aPTT), serum ferritin (nearly $1000 \mathrm{ng} / \mathrm{ml}$ ), and low level of fibrinogen, total protein, and albumin. A high titer of Ebstein-Barr virus (EBV) viral capsid antigen IgM antibody proved an acute EBV infection. Serological markers for hepatitis A, B, and C were negative, and antibody titers for autoimmune hepatitis were within normal range. Moreover, Wilson disease was ruled out by measuring serum ceruloplasmin and 24-h urine copper. Liver biopsy and bone marrow aspiration followed by biopsy was inconclusive with non-specific findings. Laboratory tests such as defective killing activity of either CD8 or NK cells, were not available in our center or elsewhere in Iran.

The proband was product of consanguineous marriage (first-degree cousins) and there were no any documented HLH disease phenotype, immune disorders, hepatic diseases and blood malignancies in the immediate and extended family. The patient was suspected as a case of HLH according to HLH-2004 protocol [9] given the fact that he fulfilled the necessary criteria mentioned above. $\mathrm{He}$ was treated with dexamethasone, cyclopsporin and etoposide, but soon after starting treatment he showed dramatic responses with resolution of fever and correction of hepatitis, pancytopenia and bleeding tendency. Gradually, the patient developed clinical signs of the central nervous system (CNS) involvements such as convulsion, ataxia, spasticity and slurred speech. But cerebral spinal fluid (CSF) analysis for cell count, protein and cytology were normal. Brain MRI with and without contrast injection revealed spots of white matter hypersignal intensities on T2 and FLAIR images which were in favor of CNS involvement in HLH [18] (Fig. 1). Thus, we added intrathecal methotrexate and hydrocortisone to his treatment regimen, and searched for an HLAmatched donor for BM transplantation.

To determine whether the patient is a case of familial $\mathrm{HLH}$, an unbiased next generation DNA sequencing which covered the entire coding exons was performed for detection of mutation in genes involved in FHL. We performed whole exome sequencing utilizing next generation sequencing on an Illumina platform on DNA sample from the patient. Detail of sample alignment is listed in Table 1. The text files of sequences were aligned using BWA aligner tool and variants were identified using GATK and annotated with the use of annovar software. 


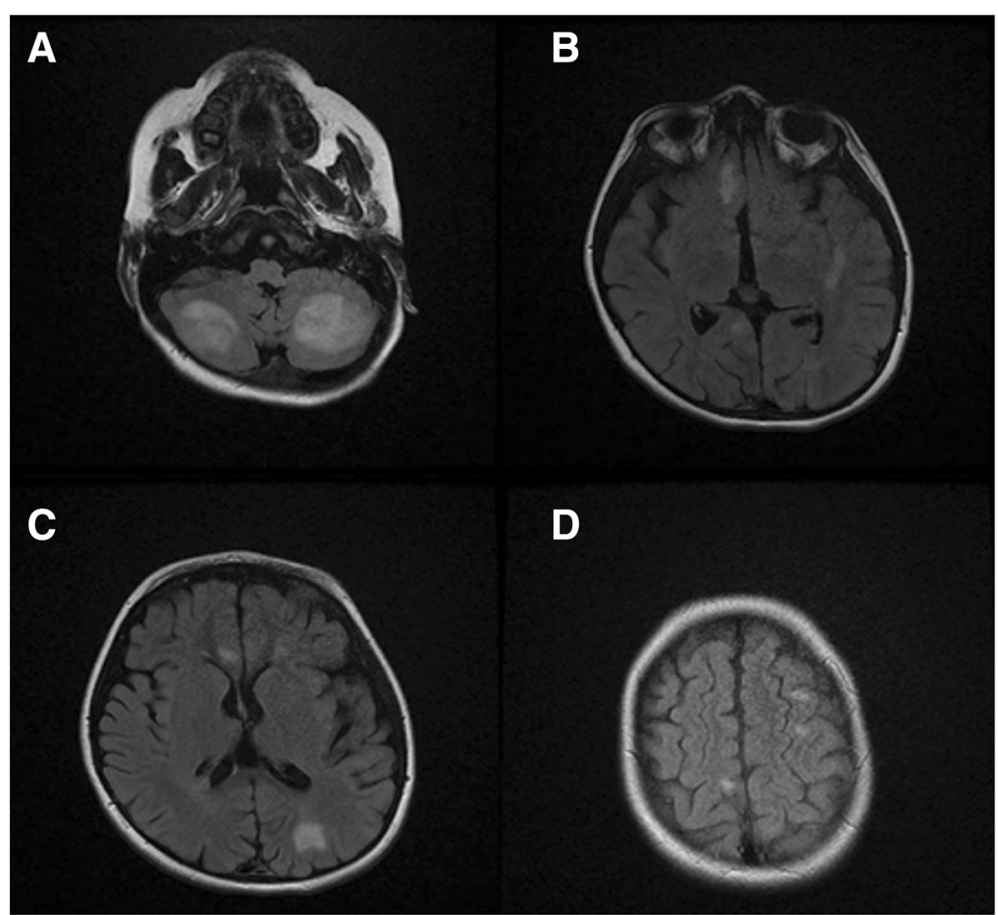

Fig. 1 a, b, c and $\mathbf{d}$ Axial Flair sequences of brain MRI, which reveal numerous variable size and irregular shape hypersignal areas involving cerebral hemispheres, cerebellar hemispheres, pones and cerebral peduncles, mostly located in the corticomedullary junction and deep white matter in favor of HLH CNS involvement

In total, more than $120 \mathrm{~K}$ annotated variants were identified with hetero/homo ratio of 1.7 , which then were filtered based on their frequency, location, functional consequences, inheritance pattern and more importantly clinical phenotype. Results revealed a novel homozygous missense mutation in PRF1 gene (NM_001083116: exon3, c.1120 T > G, p.W374G, position 72,358,357 on chromosome 10). Homozygous mutations in PRF1 gene, which is encoded for perforin 1, have been previously reported to cause type-2 of familial HLH, (OMIM number 603553) [19], having an autosomal recessive pattern of inheritance. Using Sanger sequencing, the new identified mutation was confirmed in the proband (as homozygote mutation) and his parents (as heterozygote mutation) (Fig. 2). This mutation has not previously been reported and this is the first report of mutation of $P R F 1$ gene in Iranian patients affected

Table 1 Whole exome sequencing detail of coverage and number of reads

\begin{tabular}{|c|c|c|c|}
\hline Type & Value & Type & Value \\
\hline Number of mapped reads & $41,674,840$ & Percent reads on target & $95.70 \%$ \\
\hline Percent assigned reads & $95.70 \%$ & Average reads per amplicon & 136 \\
\hline Uniformity of coverage & $86.30 \%$ & Regions with at least 100 reads & $53.69 \%$ \\
\hline Regions with at least 1 read & $99.54 \%$ & Regions with at least 500 reads & $0.70 \%$ \\
\hline Regions with at least 20 reads & $90.02 \%$ & Regions reading end-to-end & $35.97 \%$ \\
\hline Regions with no strand bias & $85.64 \%$ & Total aligned base reads & $7,342,243,527$ \\
\hline Bases in target regions & $57,742,646$ & Total base reads on target & $6,979,820,754$ \\
\hline Percent base reads on target & 0.95 & Uniformity of base coverage & 0.85 \\
\hline Average base coverage depth & 121 & Target bases with no strand bias & $78.31 \%$ \\
\hline Target base coverage at $1 \times$ & $99.18 \%$ & Target base coverage at 100x & $47.95 \%$ \\
\hline Target base coverage at $20 x$ & $87.91 \%$ & Target base coverage at 500x & $0.62 \%$ \\
\hline Percent end-to-end reads & $58.98 \%$ & mapping rate & $99.10 \%$ \\
\hline AQ17 & $92.21 \%$ & AQ20 & $87.51 \%$ \\
\hline
\end{tabular}




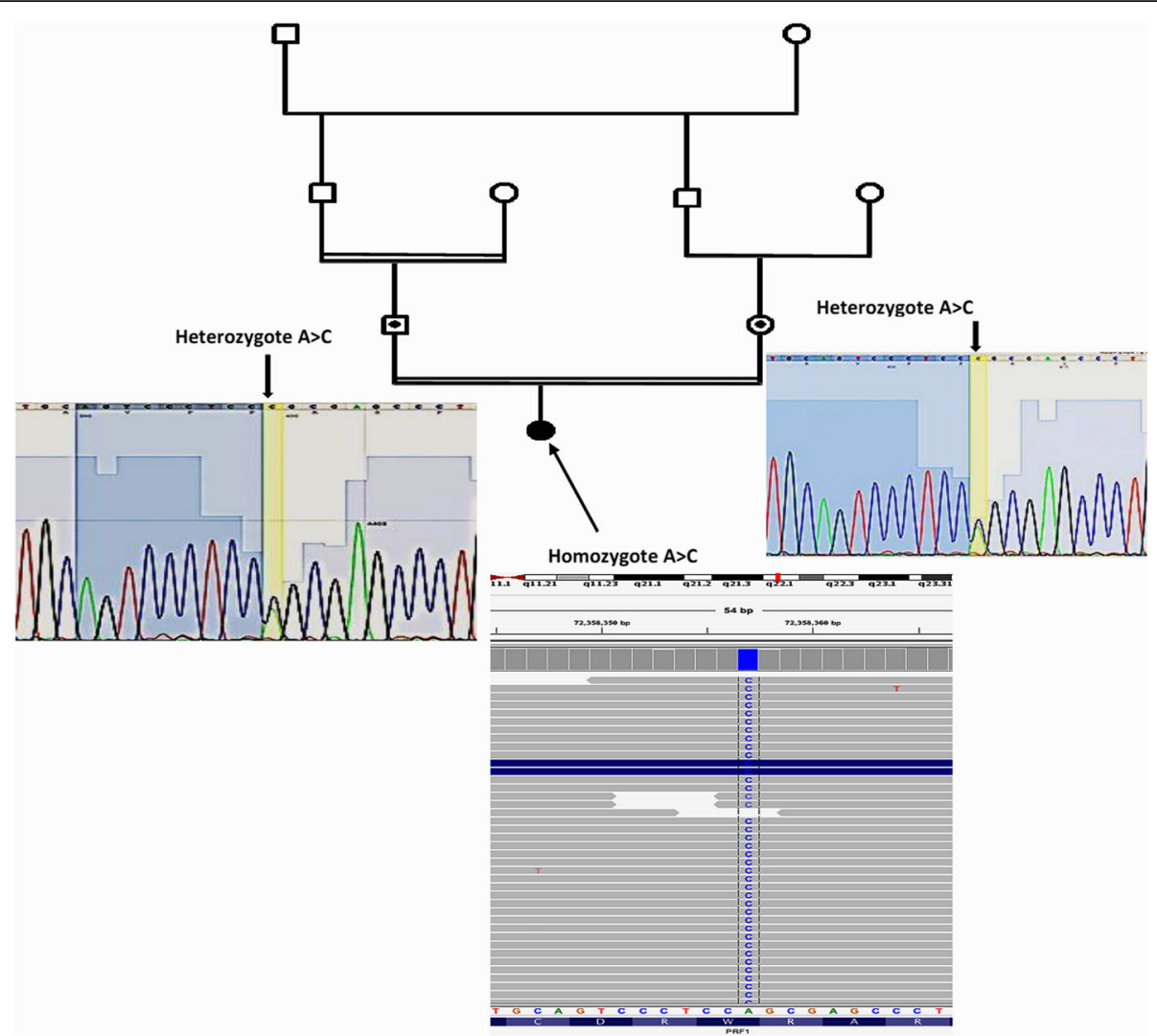

Fig. 2 The proband is a boy with hepatitis and pancytopnea and his parents has consanguineous marriage. NGS results indicate homozygous mutation in PRF1 gene in the proband as visualized using Integrative Genome Viewer (IGV) and using Sanger sequencing presence of the identified heterozygous mutation in PRF1 gene was confirmed in the parents

by HLH. Following evidences confirm that this mutation can lead to FHL2: 1-Whole exome sequencing only identified this mutation to be the main cause of FHL2 in the patient. 2- As can be seen in Fig. 2, Sanger sequencing confirmed the mutation in the proband and based on identified heterozygote mutation in his parents, the inheritance pattern must be an autosomal recessive. 3- Bioinformatics software such as polyphen, SIFT, LRT, Mutation Taster, FATHMM, Radial SVM and Mutation Assessor software are predicted that this variant will be damaging (Table 2) 4As shown in Fig. 3, the comparative amino acids alignment of perforin 1 protein across all Kingdoms using multiple sequence alignment analysis using T-Coffee Multiple Sequence Alignment Program revealed that this amino acid is highly conserved during evolution. 5 . In addition, a substitution from tryptophan amino acid with an aromatic side chain (at position 374) to glycine amino acid with a nonpolar and small hydrogen side chain can create major

Table 2 Bioinformatic analysis of new identified mutation (p.W374G) in PRF1 gene in the proband

\begin{tabular}{|c|c|c|c|c|c|c|c|c|c|}
\hline $\mathrm{Chr}^{\mathrm{a}}$ & Start & $\operatorname{Ref}^{b}$ & $\mathrm{Alt}^{\mathrm{C}}$ & Gene & Zygocity & Function & Freq $^{\text {d }}$ & dbSNP & \\
\hline 10 & 72358357 & A & C & PRF1 & Homo & Non-synonymous & 0 & 0 & \\
\hline SIFT & Pred $^{e}$ & Polyphen & Pred & Mutation Taster & Pred & $\begin{array}{l}\text { Mutation } \\
\text { Assessor }\end{array}$ & Pred & FATHMM & Pred \\
\hline 0.1 & T & 0.958 & Damaging & 1 & Damaging & 2.71 & Medium & -.2 .83 & Damaging \\
\hline VEST3 & CADD & Phred & GERP++_RS & $\begin{array}{l}\text { Raddial } \\
\text { SVM }\end{array}$ & $\begin{array}{l}\text { Raddial } \\
\text { SVM }\end{array}$ & LR_score & $\begin{array}{l}\mathrm{LR}_{-} \\
\text {pred }\end{array}$ & $\begin{array}{l}\text { Phylo } \\
\text { P46way }\end{array}$ & $\begin{array}{l}\text { Phylo } \\
\text { P100_vert }\end{array}$ \\
\hline 0.965 & 3.221 & 16.79 & 5.83 & 0.452 & Damaging & 0.707 & Damaging & 2.212 & 1.696 \\
\hline
\end{tabular}

\section{${ }^{\mathrm{a} C h r o m o s o m e}$}

${ }^{\mathrm{b}}$ Reference

cAlteration

${ }^{\mathrm{d}}$ Frequency

ePrediction 


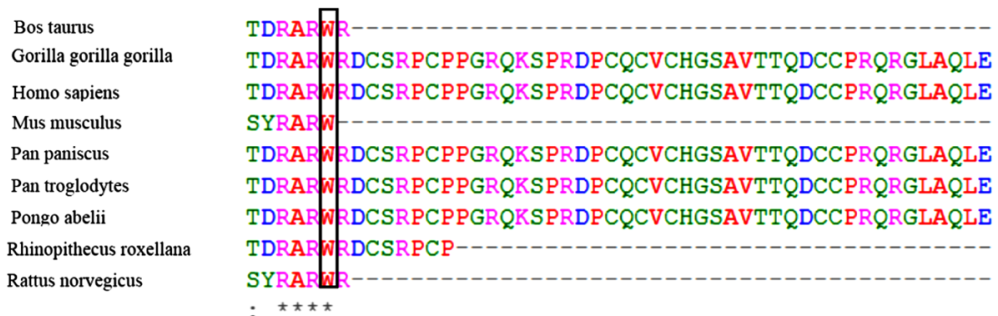

Fig. 3 Comparative amino acids alignment of perforin protein across all Kingdoms. The W374 residue is highly conserved during evolution. The conserved tryptophan residue is shown in the rectangular box. Protein sequences were obtained from National Center for Biotechnology (NCBI). Symbols: (*) —identical amino acids; (:) — just similar amino acids

problem in the protein. Thus, this mutation in PRF1 gene is extremely pathogenic in our patient with FHL2.

\section{Discussion}

PRF1 which is located on the long arm of the chromosome 10 (10q22.1) is coded for perforin 1 that is functionally and structurally similar to complement component 9 (C9) involved in the complement system. Both proteins produce transmembrane tubules and able to lyse nonspecifically various target cells. Perforin 1 is one of the essential cytolytic proteins of cytolytic granules, and it is well recognized to be a major effector molecule for T-celland natural killer-cell-mediated cytolysis. It has an important role in killing the "non-self" targets recognized by the immune system, for instance, in transplant rejection or some autoimmune diseases [20]. It plays a key role in secretory granule-dependent cell death, and in defense against virus-infected or neoplastic cells [12, 21, 22, 23]. Since the gene product is involved in killing virus-infected cells and it was impaired in our patient, his EBV infection might be due to the defect of this gene.

Mutations and variants in PRF1 gene are also documented in other disorders which include perforin deficiency [24], multiple sclerosis [25], type 1 diabetes [26], Non-Hodgkin lymphoma, and leukemia [27, 28]. Up to now, more than 115 pathogenic gene variants have been reported in this gene, mainly missense and nonsense mutations. In general, severity of the disease depends on the residual activity of the perforin $[29,30]$.

PRF1 mutations are responsible for approximately $20 \%$ of familial cases of HLH, with high frequencies in North America (approximately 50\%), Japan (40\%), and Turkey (30\% [17, 31]. FHL2 is clinically characterized by fever, edema, hepatosplenomegaly, and liver dysfunction. In addition, neurologic impairment, seizures, and ataxia are frequent in this type [32]. It has been reported that laboratory studies can show pancytopenia, coagulation abnormalities, hypofibrinogenemia, and hypertriglyceridemia [33]. However, with advances in sequencing technologies, the disease is more readily detectable and secondary prevention for families become accessible. Although heterozygous carriers are not apparently sick, they are at risk of passing this deleterious mutation into their offspring. Therefore, $P R F 1$ genetic test must be requested for individuals with abnormalities suspected for HLH and should be offered to family members of known patients who intend to have consanguineous marriage. Since there is a high rate of monogenic disorders in Iran, particularly in rural areas where first-degree marriages are more common, finding and reporting rare novel pathogenic mutations would be extremely important for subsequent prevention of inherited disorders with homozygous pattern of inheritance.

Early molecular diagnosis and initiation of treatment for familial type-2 HLH is lifesaving [34]. In addition to the prevention of new cases of inherited disease in families with consanguineous marriages, identification of novel disease-causing mutations can provide proper molecular diagnosis of HLH, which will help to consider more reliable therapeutic approaches. While there is no cure for the HLH disease, recent advances regarding other monogenic disorders have provided several potential therapeutic options which include gene therapy, cell therapy, enzyme replacement therapy and bone marrow transplant. Symptomatic and supportive treatments for the hepatic and neurological abnormalities are the current available options, but do not significantly change the clinical course and outcome. Allogeneic hematopoietic stem cell transplantation is recommended and frequently used with promising outcomes [35]. Future therapies with the use of patient-derived iatrogenic pluripotent stem cells (iPSCs) [36], combined with CRISPR/CAS9 gene editing techniques [37] might help generate hematopoietic stem cell autograph transplantation.

However, with the limited available therapeutic option for most of the HLH patients, molecular diagnosis might enable geneticists and pediatricians to provide informative genetic counseling, perform prenatal diagnosis, and implement prevention measures for such patients. Therefore, genetic counseling should be recommended to all individuals with HLH disease and families for their next pregnancies and for other family members who want to have consanguineous marriages. 


\section{Conclusions}

In summary, a rare pathogenic mutation in PRF1 gene was identified in our patient with FHL2 disorder, proving the link between PRF1 gene mutations, hepatitis, neurologic manifestations, and pancytopenia in patients with HLH. Our study may help to establish an appropriate genetic counselling and prenatal diagnosis for individuals at the high risk of HLH disorder.

\section{Abbreviations}

ALT: Alanine transaminase; APTT: Activated partial thromboplastin time: AST: Aspartate transaminase; CNS: Central nervous system; CSF: Cerebral spinal fluid; EBV: Epstein-Barr virus; FHL: Familial Hemophagocytic Lymphohistiocytosis; HLH: Hemophagocytic Lymphohistiocytosis; iPSCs: latrogenic pluripotent stem cells; LDH: Lactate dehydrogenase; MRI: Magnetic resonance imaging; PRF1: Perforin 1; PT: Prothrombin time

\section{Acknowledgements}

We would like to thank patients' family for their willingness to take part in this study. We would like to thank Comprehensive Genetic Center personnel and physicians for their help and discussion.

\section{Funding}

This work was partly supported by the US NIH NINDS R01NS081208-01A1 awarded to Mohammad Ali Faghihi. Additionally, this work was partly supported by the NIMAD research grant awarded to Mohammad Ali Faghihi. The funding agencies has no role in the design of the study and collection, analysis, and interpretation of data.

\section{Availability of data and materials}

All data including NGS sequencing raw and analyzed data and sanger sequencing files will be provided to interested scientist upon request. The identified mutation will be uploaded into HGMC database as well as ClinVar website (Submission ID: SUB2423865).

\section{Authors' contributions}

MAF conceived and designed the study, collected, assembled and interpreted data and wrote the manuscript. MRB and NSA clinically evaluated the patient's interpreted data and wrote the manuscript. FM and HF performed the experiments and helped with writing of the manuscript. HD helped critically in revising the manuscript. All authors read and approved the final manuscript.

\section{Competing interests}

The authors declare that they have no competing interests.

\section{Consent for publication}

Patient's father has signed informed consent to participate in this study and to allow us to publish the result of study.

\section{Ethics approval and consent to participate}

Ethic committee at Shiraz University of Medical Sciences, Comprehensive Medical Genetic center has approved the study and parents of affected individual has signed written consent indicating their voluntary contribution to the current study.

\section{Publisher's Note}

Springer Nature remains neutral with regard to jurisdictional claims in published maps and institutional affiliations.

\section{Author details}

${ }^{1}$ Hematology Research Center, Shiraz University of Medical Sciences, Shiraz, Iran. ${ }^{2}$ Center for Therapeutic Innovation, Department of Psychiatry and Behavioral Sciences, University of Miami Miller School of Medicine, 1501 NW 10th Ave, BRB 508, Miami, FL 33136, USA. ${ }^{3}$ Comprehensive Medical Genetic Center, Shiraz University of Medical Sciences, Shiraz, Iran.
Received: 29 September 2016 Accepted: 8 April 2017

Published online: 03 May 2017

\section{References}

1. Janka GE. Familial and acquired hemophagocytic lymphohistiocytosis. Annu Rev Med. 2012;63:233-46.

2. Henter II, Elinder G, Soder O, Ost A. Incidence in Sweden and clinical features of familial hemophagocytic lymphohistiocytosis. Acta Paediatr Scand. 1991;80(4):428-35.

3. Gurgey A, Aytac S, Balta G, Oguz KK, Gumruk F. Central nervous system involvement in Turkish children with primary hemophagocytic lymphohistiocytosis. J Child Neurol. 2008;23(11):1293-9.

4. Ishii E, Ohga S, Tanimura M, Imashuku S, Sako M, Mizutani S, Miyazaki S. Clinical and epidemiologic studies of familial hemophagocytic lymphohistiocytosis in Japan. Japan LCH study group. Med Pediatr Oncol. 1998;30(5):276-83.

5. Gurgey A, Gogus S, Ozyurek E, Aslan D, Gumruk F, Cetin M, Yuce A, Ceyhan M, Secmeer $G$, Yetgin $S$, et al. Primary hemophagocytic lymphohistiocytosis in Turkish children. Pediatr Hematol Oncol. 2003;20(5):367-71.

6. Janka G. Hemophagocytic lymphohistiocytosis: when the immune system runs amok. Klin Padiatr. 2009;221(5):278-85.

7. Rosado FG, Kim AS. Hemophagocytic lymphohistiocytosis: an update on diagnosis and pathogenesis. Am J Clin Pathol. 2013;139(6):713-27.

8. Henter Jl, Elinder G, Ost A. Diagnostic guidelines for hemophagocytic lymphohistiocytosis. The FHL study group of the histiocyte society. Semin Oncol. 1991;18(1):29-33.

9. Henter J, Horne A, Arico M, Egeler RM, Filipovich AH, Imashuku S, Ladisch S, McClain K, Webb D, Winiarski J, et al. HLH-2004: diagnostic and therapeutic guidelines for hemophagocytic lymphohistiocytosis. Pediatr Blood Cancer. 2007:48(2):124-31.

10. Janka GE, Schneider EM. Modern management of children with haemophagocytic lymphohistiocytosis. Br J Haematol. 2004;124(1):4-14.

11. Voskoboinik I, Smyth MJ, Trapani JA. Perforin-mediated target-cell death and immune homeostasis. Nat Rev Immunol. 2006;6(12):940-52.

12. Stepp SE, Dufourcq-Lagelouse R, Le Deist F, Bhawan S, Certain S, Mathew PA, Henter J, Bennett M, Fischer A, de Saint BG, et al. Perforin gene defects in familial hemophagocytic lymphohistiocytosis. Science. 1999:286(5446):1957-9.

13. Feldmann J, Callebaut I, Raposo G, Certain S, Bacq D, Dumont C, Lambert N, Ouachee-Chardin M, Chedeville G, Tamary H, et al. Munc13-4 is essential for cytolytic granules fusion and is mutated in a form of familial hemophagocytic lymphohistiocytosis (FHL3). Cell. 2003;115(4):461-73.

14. zur Stadt U, Rohr J, Seifert W, Koch F, Grieve S, Pagel J, Strauss J, Kasper B, Nurnberg G, Becker C, et al. Familial hemophagocytic lymphohistiocytosis type 5 (FHL-5) is caused by mutations in Munc18-2 and impaired binding to syntaxin 11. Am J Hum Genet. 2009;85(4):482-92.

15. zur Stadt U, Schmidt S, Kasper B, Beutel K, Diler AS, Henter Jl, Kabisch H, Schneppenheim R, Nurnberg P, Janka G, et al. Linkage of familial hemophagocytic lymphohistiocytosis (FHL) type-4 to chromosome $6 \mathrm{q} 24$ and identification of mutations in syntaxin 11. Hum Mol Genet. 2005;14(6):827-34

16. Cote M, Menager MM, Burgess A, Mahlaoui N, Picard C, Schaffner C, Al-Manjomi F, Al-Harbi M, Alangari A, Le Deist F, et al. Munc18-2 deficiency causes familial hemophagocytic lymphohistiocytosis type 5 and impairs cytotoxic granule exocytosis in patient NK cells. J Clin Invest. 2009;119(12):3765-73.

17. Gholam C, Grigoriadou S, Gilmour KC, Gaspar HB. Familial haemophagocytic lymphohistiocytosis: advances in the genetic basis, diagnosis and management. Clin Exp Immunol. 2011;163(3):271-83.

18. Guandalini M, Butler A, Mandelstam S. Spectrum of imaging appearances in Australian children with central nervous system hemophagocytic lymphohistiocytosis. J Clin Neurosci. 2014;21(2):305-10.

19. Madkaikar M, Gupta M, Dixit A, Patil V. Predominant Neurological Manifestations Seen in a Patient With a Biallelic Perforin 1 Mutation (PRF1; p.R225W). J Pediatr Hematol Oncol. 2016;39(2):143-146.

20. Yang SL, Xu XJ, Tang YM, Song H, Xu WQ, Zhao FY, Shen DY. Associations between inflammatory cytokines and organ damage in pediatric patients with hemophagocytic lymphohistiocytosis. Cytokine. 2016:85:14-7.

21. Dotiwala F, Mulik S, Polidoro RB, Ansara JA, Burleigh BA, Walch M, Gazzinelli RT, Lieberman J. Killer lymphocytes use granulysin, perforin and granzymes to kill intracellular parasites. Nat Med. 2016;22(2):210-6.

22. Zhou F. Perforin: more than just a pore-forming protein. Int Rev Immunol. 2010;29(1):56-76. 
23. Menasche G, Feldmann J, Fischer A, de Saint BG. Primary hemophagocytic syndromes point to a direct link between lymphocyte cytotoxicity and homeostasis. Immunol Rev. 2005;203:165-79.

24. Tesi B, Chiang SC, El-Ghoneimy D, Hussein AA, Langenskiold C, Wali R, Fadoo Z, Silva JP, Lecumberri R, Unal S, et al. Spectrum of atypical clinical presentations in patients with biallelic PRF1 missense mutations. Pediatr Blood Cancer. 2015;62(12):2094-100.

25. Camina-Tato M, Morcillo-Suarez C, Bustamante MF, Ortega I, Navarro A, Muntasell A, Lopez-Botet M, Sanchez A, Carmona P, Julia E, et al. Genderassociated differences of perforin polymorphisms in the susceptibility to multiple sclerosis. J Immunol. 2010;185(9):5392-404.

26. Orilieri E, Cappellano G, Clementi R, Cometa A, Ferretti M, Cerutti E, Cadario F, Martinetti M, Larizza D, Calcaterra V, et al. Variations of the perforin gene in patients with type 1 diabetes. Diabetes. 2008;57(4):1078-83.

27. Mhatre S, Madkaikar M, Jijina F, Ghosh K. Unusual clinical presentations of familial hemophagocytic lymphohistiocytosis type-2. J Pediatr Hematol Oncol. 2014;36(8):e524-527.

28. Mhatre S, Madkaikar M, Desai M, Ghosh K. Spectrum of perforin gene mutations in familial hemophagocytic lymphohistiocytosis (FHL) patients in India. Blood Cells Mol Dis. 2015;54(3):250-7.

29. Ishii E, Ohga S, Imashuku S, Kimura N, Ueda I, Morimoto A, Yamamoto K Yasukawa M. Review of hemophagocytic lymphohistiocytosis $(H L H)$ in children with focus on Japanese experiences. Crit Rev Oncol Hematol. 2005;53(3):209-23.

30. Zhang K, Filipovich AH, Johnson J, Marsh RA, Villanueva J. Hemophagocytic Lymphohistiocytosis, Familial. In: Pagon RA, Adam MP, Ardinger HH, Wallace SE, Amemiya A, Bean LJH, Bird TD, Fong CT, Mefford HC, Smith RJH, et al. editiors. GeneReviews (R). Seattle: University of Washington, Seattle; 1993-2017. 2006 Mar 22 [updated 2013 Jan 17].

31. Morimoto A, Nakazawa Y, Ishii E. Hemophagocytic lymphohistiocytosis: pathogenesis, diagnosis, and management. Pediatr Int. 2016;58:817.

32. Ishii E. Hemophagocytic lymphohistiocytosis in children: pathogenesis and treatment. Front Pediatr. 2016;4:47.

33. Hayden A, Park S, Giustini D, Lee AY, Chen LY. Hemophagocytic syndromes (HPSs) including hemophagocytic lymphohistiocytosis (HLH) in adults: a systematic scoping review. Blood Rev. 2016;30:411.

34. Yasumi T, Shibata H, Shimodera S, Heike T. [Heterogeneity of HLH pathophysiology and treatment strategies]. Rinsho Ketsueki. 2015:56(10):2248-57.

35. Jiang MY, Guo X, Sun SW, Li Q, Zhu YP. Successful allogeneic hematopoietic stem cell transplantation in a boy with X-linked inhibitor of apoptosis deficiency presenting with hemophagocytic lymphohistiocytosis: a case report. Exp Ther Med. 2016;12(3):1341-4.

36. Avior Y, Sagi I, Benvenisty N. Pluripotent stem cells in disease modelling and drug discovery. Nat Rev Mol Cell Biol. 2016;17(3):170-82.

37. Wang F, Qi LS. Applications of CRISPR genome engineering in cell biology Trends Cell Biol. 2016;26:875.

\section{Submit your next manuscript to BioMed Central and we will help you at every step:}

- We accept pre-submission inquiries

- Our selector tool helps you to find the most relevant journal

- We provide round the clock customer support

- Convenient online submission

- Thorough peer review

- Inclusion in PubMed and all major indexing services

- Maximum visibility for your research

Submit your manuscript at www.biomedcentral.com/submit
( BiolMed Central 